\title{
FESTAS DO ROSÁRIO COMO PATRIMÔNIO: entre o vivido e a prática estatal
}

\author{
Mariana Ramos de Morais * (https://orcid.org/0000-0002-1604-2366)
}

\begin{abstract}
Este artigo aborda o registro das festas dedicadas ao Rosário de Maria como um patrimônio cultural imaterial do Brasil. Desde 2008, está em curso o processo de patrimonialização dessas festas no âmbito nacional. Essa ação se inscreve no controverso domínio do patrimônio cultural imaterial difundido em escala global pela UNESCO e que se baseia em um discurso que confere à globalização a capacidade de homogeneizar as culturas. A diversidade cultural do planeta estaria, assim, ameaçada. Diante dessa ameaça, haveria a necessidade de salvaguardar certas práticas culturais. Porém, no referido caso, trata-se de festas. As festas, notadamente as religiosas, são entendidas como o momento da produção do fato coletivo, da vida. E, dada a sua própria dinâmica, as festas não estariam em vias de desaparecimento. Dessa forma, o argumento estatal para registrar as festas como patrimônio entra em tensão com sua própria dinâmica.
\end{abstract}

Palavras-Chave: Festa. Rosário de Maria. Patrimônio cultural imaterial. Salvaguarda. Globalização.

\section{INTRODUÇÃO}

Em 2008, foi dado início ao processo de registro das Congadas de Minas como patrimônio cultural brasileiro. As congadas, seguindo o termo adotado pelo Instituto do Patrimônio Histórico e Artístico Nacional (IPHAN), são festas dedicadas a Nossa Senhora do Rosário, que, sob essa invocação, é louvada, sobretudo pelos negros, desde os tempos coloniais no Brasil. Segundo um levantamento feito por esse órgão, somente no estado de Minas Gerais, 701 festas do Rosário são realizadas atualmente, nomeadas também como congado, congo, reinado e, como já foi mencionado, congada, podendo receber ainda outras denominações. O processo iniciado pelo IPHAN tem por fim a inscrição dessas festas em um dos seus livros de registros que se ocupam dos saberes, dos lugares, das celebrações ou das formas de expressão. E, concluído o processo, as Congadas de Minas passarão a ser consideradas como

\footnotetext{
* Pontifícia Universidade Católica de Minas Gerais. Programa de Pós-Graduação em Ciências Sociais.

Avenida Itaú, 505 (3ํ andar). Dom Cabral. Cep: 30535012. Belo Horizonte - Minas Gerais - Brasil. marianaramosdemorais@gmail.com
}

mais um dos patrimônios culturais imateriais brasileiros.

No Brasil, o registro dos patrimônios culturais imateriais foi instituído em 2000, ${ }^{1}$ sob a influência de um discurso que conferia à globalização - considerada uma das consequências do capitalismo e, ao mesmo tempo, uma das forças inerentes a ele - a capacidade de homogeneizar as diferenças entre as culturas. Conforme esse discurso, que ganhou destaque nas décadas finais do século XX, a ameaça de perda da diversidade cultural no planeta era iminente. Era preciso, assim, preservar as culturas ditas tradicionais, como defendeu - e ainda defende - a Organização das Nações Unidas para a Educação, a Ciência e a Cultura (UNESCO), órgão que difunde, em escala global, as normas que buscam traduzir a experiência humana, e, portanto, coletiva, em patrimônio cultural classificado como material e imaterial.

${ }^{1}$ Data de 30 de novembro de 1937 o Decreto-Lei 25, que estabelece a proteção legal do patrimônio nacional (Brasil, 1937). Esse Decreto ainda se encontra em vigor. A partir da Constituição Federal de 1988 (Brasil, 1988), considera-se ser o patrimônio cultural brasileiro constituído de bens culturais materiais e imateriais. Em 4 de agosto de 2000, foi publicado o Decreto $n^{\circ} 3.551$ (Brasil, 2000), instituindo o registro dos bens culturais de natureza imaterial. 
A alegoria da perda, sob a qual havia se baseado a constituição do patrimônio cultural adjetivado material, pois fundado na monumentalidade, era transposta para a constituição de outro patrimônio, afirmado também como cultural, mas que, por ter como base a pujança do vivido, passou a ser acrescido do termo imaterial. Sob essa justificativa, multiplicaram-se as ações tendo como foco as práticas culturais consideradas tradicionais, que, no Brasil, muitas vezes, se referem àquelas advindas dos povos indígenas e da população negra. Danças, rituais, lugares sagrados, ofícios e festejos passaram a integrar a lista dos patrimônios nacionais, antes restritos a elementos de "pedra e cal”.

Em 2018, quarenta e um (41) bens culturais ditos imateriais constavam nessa lista. São bens culturais que, seguindo o discurso da própria política patrimonial, necessitavam de salvaguarda. No Dicionário Houaiss (2019), esse substantivo feminino - salvaguarda - recebe o seguinte sentido: "série de ações cujo objetivo é garantir a integridade e a perenidade de algo; defesa, preservação, proteção". Dessa forma, estando as Congadas de Minas, ou as festas dedicadas ao Rosário de Maria, em processo de registro como patrimônio cultural imaterial, elas estariam sendo foco de ações vi$\stackrel{\rightarrow}{\vec{I}}$ sando à garantia de sua integridade e de sua perenidade. Pressupõe-se, assim, que elas precisariam ser preservadas, protegidas, diante da ainda constante ameaça da globalização.

No entanto, no processo de registro em questão, trata-se de festas, em especial, de festas religiosas, entendidas - a partir de Durkheim (1996) e seguindo as interpretações de autores que buscam pensá-las a luz da realidade brasileira (Amaral, 1998; Da Matta, 1978; Perez, 2011, 2015) - como o momento mesmo da produção do fato coletivo. Nesse momento, a ordem pré-estabelecida adquire um ordenamento outro que parece destituir o que estava posto, mas que, em certa medida, parte dele para gerar novos dispositivos acionados individual e coletivamente. As festas, desse modo, são capazes de recriar a si próprias e, consequentemente, a vida social. E, assim, elas contrariam as teorias que pregam sua morte diante da expansão do capitalismo. Notadamente, as festas dedicadas ao Rosário de Maria exibem sua profusão, pois, tal como indica o órgão gestor do Patrimônio no Brasil, em Minas Gerais ocorrem, repito, 701 festas.

$\mathrm{O}$ argumento que permeia os processos de patrimonialização, fundado na alegoria da perda, conflita com a experiência coletiva proporcionada nas e pelas festas dedicadas ao Rosário de Maria. Trata-se de uma tensão entre o vivido e a prática estatal, como sugere o subtítulo deste artigo, que foi elaborado a partir de minha experiência de pesquisa com diferentes grupos que realizam festas dedicadas ao Rosário e que estão envolvidos em processos de patrimoniazalição não apenas na esfera nacional. ${ }^{2}$

Apresento minhas reflexões sobre a tensão expressa no processo de registro das festas dedicadas ao Rosário de Maria como patrimônio cultural do Brasil em quatro etapas. Primeiramente, faço breves apontamentos sobre a política patrimonial no Brasil, relacionando-a ao contexto global no que se refere aos ditames da UNESCO. Sigo destacando as variações das festas dedicadas ao Rosário de Maria, para demonstrar como isso implica tanto a maneira como a literatura as tem abordado, quanto o seu processo de patrimonialização. Na sequência, focalizo certos momentos desse processo nos quais essa tensão é explicitada. Ao final, apresento um caso local, de uma Irmandade de Nossa Senhora do Rosário, classificada como patrimônio cultural de Belo Horizonte, a capital mineira, com vistas a lançar luz ao processo em curso no âmbito nacional.

2 Desde 2010, realizo pesquisas que envolvem a patrimonialização de práticas religiosas afro-brasileiras, mantendo contato com os diferentes atores envolvidos nos processos, incluindo as comunidades, bem como gestores públicos, intelectuais, integrantes de entidades da sociedade civil. Privilegio métodos qualitativos, especialmente o trabalho de campo aliando, à observação participante e às conversas informais, entrevistas e análise documental. $\mathrm{O}$ presente artigo apresenta, assim, reflexões que são fruto dessa experiência continuada de pesquisa, sendo os dados referentes às festas do Rosário produzidos até 2018, quando da submissão deste trabalho. 


\section{POLÍTICA PATRIMONIAL}

A política de patrimônio cultural no Brasil foi criada nos anos 1930 sob um ideal nacionalista. Um ideal sustentado não apenas por um governo, mas também por intelectuais que defendiam a necessidade da constituição de um patrimônio cultural brasileiro como resposta a uma situação de iminente destruição e desaparecimento de obras de arte e monumentos históricos no território nacional. Ou seja, a política se baseava na "retórica da perda", fazendo-se, aqui, referência à expressão cunhada por José Reginaldo Santos Gonçalves (1996) ao analisar as narrativas sobre a formulação e a implementação da política patrimonial brasileira. ${ }^{3}$

Na virada da década de 1970 para a de 1980, quando tal política passou por uma reformulação, constava novamente, nas narrativas acerca do patrimônio nacional, a ameaça de uma perda, no caso, da identidade nacional brasileira, devido ao processo de globalização, que poderia levar a uma homogeneização cultural. Assim, tornava-se urgente, naquele momento, a adoção por parte do governo de medidas protetivas e de valorização dos "componentes fundamentais" da cultura brasileira. Tais "componentes" eram considerados como os elementos por meio dos quais a singularidade do "caráter" nacional brasileiro seria definida. E tal singularidade advinha da diversidade cultural brasileira, expressa, por exemplo, nas diferentes formas de "cultura popular" (Gonçalves, 1996, p. 103-105). À época, já se buscava desenvolver ações com vistas à valorização e à manutenção da dita diversidade cultural.

Esse argumento se assemelha ao que, a partir dos anos 2000, passou a sustentar a constituição de um patrimônio cultural imaterial não somente no Brasil como também no âmbito da UNESCO e nos demais países signatários da Convenção para Salvaguarda do Patrimônio Cultural Imaterial, datada de 2003

${ }^{3}$ Sobre a construção da política de patrimônio cultural no Brasil, ver também Arantes (1984), Rubino (1992), Fonseca (1997), Chuva (2009).
(UNESCO, 2003). ${ }^{4}$ A defesa da diversidade cultural frente à suposta ameaça da globalização é apontada como um dos principais objetivos da convenção. Vale mencionar também que a convenção teve como mote o estabelecimento de um equilíbrio entre as representações dos países do Norte e dos países do Sul na composição do patrimônio cultural mundial. Trata-se de uma operação geopolítica que colocou em questão a concepção ocidental de patrimônio, fundada nos grandes monumentos e na sua excepcionalidade, ao mesmo tempo em que buscou conceder uma dada representatividade a diferentes grupos sociais, bem como aos seus elementos culturais (Tornatore, 2010).

A constituição dos patrimônios culturais, materiais ou imateriais, está imbricada a um projeto político que pode ser de um grupo ou de uma nação. Tanto em um caso quanto no outro, tal projeto não visa somente à produção de um conhecimento, uma vez que a constituição dos patrimônios culturais é a expressão de um poder (Bortolotto, 2011a). Trata-se também de uma ação. E, sendo uma ação, o tombamento de um monumento, ou simplesmente o reconhecimento de um valor de um bem cultural, tem suas consequências (Fabre, 1997). O desenvolvimento do turismo relacionado ao bem patrimonializado pode ser pensado aqui como uma dessas consequências. Como também o uso estratégico dos instrumentos legais relativos à política de patrimônio cultural pelos grupos envolvidos na sua elaboração e na sua execução.

Devido à maneira como a política pública é institucionalizada, seu funcionamento incita a articulação de políticos, gestores públicos, intelectuais, integrantes de entidades da sociedade civil e de grupos cujo bem cultural é foco da ação patrimonial. Esses últimos são, conforme a mencionada convenção da UNESCO, os responsáveis por criar, manter e transmitir o patrimônio cultural imaterial. No caso específico

${ }^{4}$ Lembrando aqui que, no caso brasileiro, as normativas acerca do patrimônio cultural imaterial antecedem a Convenção de 2003 da UNESCO, que foi ratificada pelo Brasil em 2006. Para relatos e críticas sobre o processo de instituição do patrimônio cultural imaterial no Brasil (Cf. Abreu; Chagas, 2009; Sant'Anna, 2012). 
deste artigo, são esses os grupos que realizam as festas dedicadas a Nossa Senhora do Rosário.

\section{AS FESTAS E SUAS VARIAÇÕES ${ }^{5}$}

Em Minas Gerais, aos olhos de quem de longe observa, parece haver, em cada cidade, um festejo dedicado ao Rosário de Maria, dada a sua crescente exposição midiática. Constituído por 853 municípios, esse estado do Sudeste brasileiro tem uma área de 586 mil quilômetros quadrados e faz divisa com seis outros estados da Federação. Cachoeiras cortam suas serras dilaceradas pela exploração dos metais preciosos, seja o ouro do passado ou o nióbio do presente. Os rios, que antes corriam soltos, transformam-se em canais de concreto nos centros urbanos. A ação humana que tanto deixa marcas em suas paisagens somente ainda não foi capaz de fazer com que suas montanhas sejam banhadas pelo mar. E é do mar que vem Nossa Senhora do Rosário, como cantam seus devotos em festa, ao se referirem, em seus ritos, à travessia da África ao Novo Mundo, seguindo a rota de seus antepassados. Mas a ausência de mar nas Gerais não impede que a Virgem Santa chegue até os seus devotos, os Pretinhos do Rosário, como por vezes se autodenominam.

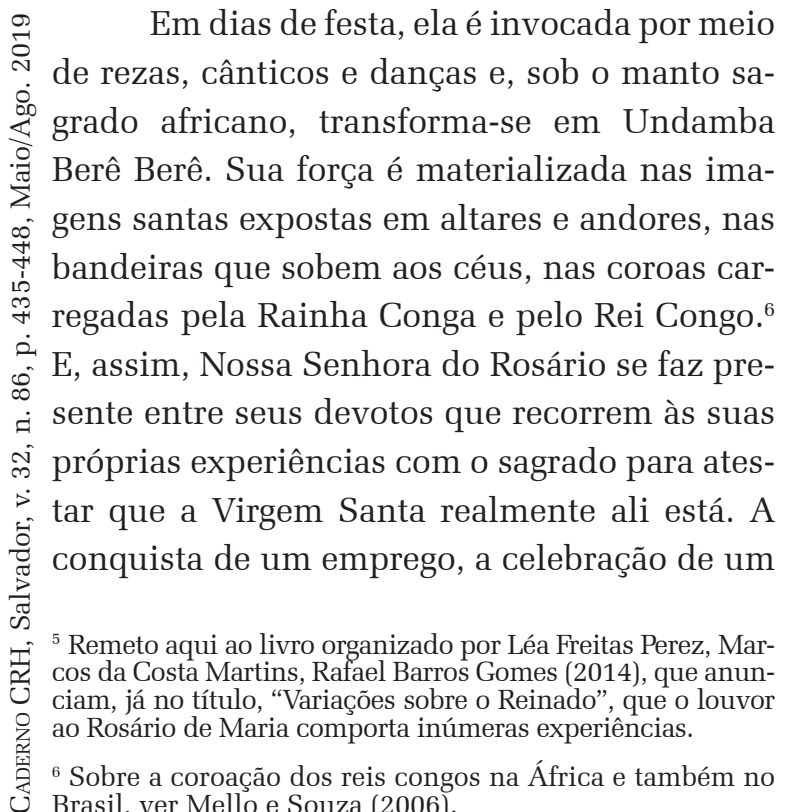

casamento, a concepção de um filho e a cura de uma enfermidade são dádivas creditadas a ela, segundo aqueles que têm fé. Para alguns, a graça foi ter a visão da própria Maria, com seu Rosário e o Jesus Menino nos braços. Essa graça pode até ser reservada a poucos, mas é ativada por cada devoto que transmite a narrativa dessa aparição divina. Uma narrativa que tem variadas versões, como também variados são os modos de festejar o Rosário de Maria. ${ }^{7}$

As festas em seu louvor congregam diferentes grupos, que são chamados de guardas, ternos ou bandas, diferenciando-se uns dos outros pelo toque da caixa (o tambor), pelos instrumentos musicais, pela forma de dançar, pelas cantigas que entoam, pelas vestimentas, pelas funções rituais. Assim, distinguem-se as guardas de congo, catopé, caboclinho, vilão, marujada, moçambique, além do candombe, considerada a guarda mais antiga, mas que não sai em cortejo pelas ruas das cidades como as demais. Nem todas as festas são realizadas por essa gama de guardas. A presença das guardas pode variar de caso a caso, o que faz com que o Rosário de Maria contemple inúmeras variações festivas.

Segundo o IPHAN, existem em Minas Gerais 1.174 grupos que realizam festas do Rosário em 332 municípios mineiros. De fato, as festas não abarcam todos os municípios do Estado, como pode parecer a um observador externo. Esses dados constam do Levantamento Preliminar do Inventário Nacional de Referências Culturais (INRC) $)^{8}$ realizado pelo IPHAN, como um dos procedimentos necessários ao registro das Congadas de Minas como patrimônio imaterial do Brasil. ${ }^{9}$

${ }^{7}$ Há narrativas em que de Nossa Senhora do Rosário apare-
ce no mar, outras no rio ou mesmo em uma gruta, em uma
lapinha. Nos estudos sobre o Reinado, de maneira geral,
sempre constam variações dessa narrativa. Algumas delas
estão registradas em Martins, L. (1997); Lucas (2014); Ki-
ddy (2005); Silva (2012); Perez, Martins e Gomes (2014).
${ }^{8}$ O resultado desse levantamento foi apresentado no “Se-
minário Saberes do Sagrado: Irmandades do Rosário e o
Registro Patrimonial”, realizado em 2015, em Belo Hori-
zonte. Esse encontro, que integrou o projeto multinacional
"Salvaguardia del PCI relacionado a música, canto, danza
de comunidades afrodescendentes en los países del CRES-
PIAL (Centro Regional para a Salvaguarda do Patrimônio
Cultural Imaterial da América Latina)”.
${ }^{9}$ Os dados apresentados aqui podem não corresponder 
Esse processo teve início em 2008 a partir da solicitação da Prefeitura de Uberlândia, com o apoio de outras cinco prefeituras e uma associação que representa grupos que realizam festas do Rosário. ${ }^{10}$ Os solicitantes são de cidades situadas no oeste de Minas Gerais, nas regiões vizinhas do Alto do Paranaíba e do Triângulo Mineiro. Nessas localidades, tais festas são geralmente chamadas de "congadas", termo que acabou sendo adotado para intitular o processo de registro no IPHAN. No entanto, esse é apenas um dos termos que nomeiam as festas do Rosário. Em outras regióes do Estado, como foi dito, essas festas são designadas como congado, congo ou reinado, para citar alguns exemplos sem querer aqui esgotá-los. Nota-se: variadas também são as maneiras de nomear as festas dedicadas ao Rosário de Maria.

Se, por vezes, os termos reinado, congado, congada ou congo podem ser usados como sinônimos da festa dedicada ao Rosário de Maria, cada um deles pode também receber outros sentidos, segundo seus praticantes. Reinado, por exemplo, refere-se também ao trono coroado em conjunto com seu séquito, ou seja, à comunidade religiosa formada a partir da coroação do Rei Congo e da Rainha Conga. Congado designa, em certas ocasiões, o grupo de devotos que organiza um festejo em louvor a Nossa Senhora do Rosário. Entre aqueles que festejam o Rosário de Maria, há quem afirme que nem todo congado é reinado, buscando diferenciar os grupos em que há a instauração de um reino a partir da coroação dos reis e rainhas, ou seja, os reinados, dos grupos formados apenas para um festejo, que seriam os congados.

Talvez seja o próprio Rosário de Maria o signo que transpassa essas festas fundadas e

à totalidade das festas hoje realizadas em Minas, devido à maneira como o levantamento foi realizado. A equipe responsável não teve condições de visitar todos os 853 municípios do Estado. Assim, parte do levantamento foi realizado via contato telefônico com prefeituras, paróquias e entidades representativas dos praticantes das "Congadas de Minas”.

${ }^{10}$ Trata-se das prefeituras de Uberaba, Campos Altos, Ibiá, Frutal e Monte Alegre de Minas, e da Associação dos Congos e dos Moçambiques Nossa Senhora do Rosário da cidade de Ibiá. circunscritas por tantas variações. O Rosário de Maria é a própria força sagrada invocada para a proteção daqueles que nela acreditam. E trata-se também de um objeto ritual. É um cordão de contas usado no acompanhamento das recitações das orações dedicadas a Maria e que os devotos devem portar em seu pescoço. Cada conta representa um devoto, sem que haja uma correspondência direta entre o total de contas e o total de devotos. E, quando essas contas são unidas no cordão, representam o conjunto de devotos e, ao mesmo tempo, a própria força sagrada que os protege e que deles também emana. No entanto, cada cordão pode ser feito de um material diferente, como miçangas, cristais, pedras, sementes, remetendo, novamente, às suas variações.

Tais variações são explicitadas à medida que o processo de registro das festas do Rosário se desenrola. Em 2018, sua tramitação completou dez anos - um processo lento, devido a entraves burocráticos e políticos. ${ }^{11}$ Além do Levantamento Preliminar do Inventário Nacional de Referências Culturais, que buscou mapear as festas no Estado, a seção mineira do IPHAN criou um grupo de trabalho, com a presença de pesquisadores do tema, e seus técnicos estiveram reunidos com integrantes de grupos que realizam os festejos e também com representantes de algumas prefeituras de cidades onde esses festejos ocorrem. Após a finalização do Levantamento Preliminar do INRC, a seção do IPHAN, em Minas Gerais, decidiu que seria necessário realizar encontros regionais com os integrantes dos grupos para buscar contemplar suas variações. Foram sete as cidades escolhidas para sediar tais encontros: Uberlândia, Santo Antônio do Monte, Divinópolis, Sete Lagoas, Montes Claros, São João Del Rei e Machado. No entanto, apenas dois encontros foram realizados, ambos em 2018, sendo um em Montes Claros e outro em Uberlândia. ${ }^{12}$ ${ }^{11}$ Quando da submissão deste artigo, em 2018, não havia
uma previsão para o fim desse processo.

${ }^{12}$ Ainda há a previsão de se realizar um encontro em Belo Horizonte, reunindo os congadeiros da capital e do entorno metropolitano. No entanto, ainda não havia uma data estabelecida quando da conclusão deste artigo. 
Foi a partir dessas iniciativas que o IPHAN iniciou o contato, ainda que breve, com outros grupos envolvidos nessa patrimonialização, e não apenas os solicitantes. Tal contato, aliás, pode ter contribuído para que as variações do Rosário de Maria começassem a repercutir, em certa medida, no processo de registro. Observa-se, por exemplo, que a expressão que designa o bem cultural que é objeto de patrimonialização, no caso as Congadas de Minas, foi relativizada em alguns documentos que abordam o tema. No encontro realizado em Uberlândia, por exemplo, esse bem cultural em processo de patrimonialização foi nomeado "Congado/Congadas/Reinados", conforme consta na apresentação feita pela equipe técnica do IPHAN na ocasião. ${ }^{13}$

Outros dois casos merecem menção. A funcionária do IPHAN, seção Minas Gerais, que acompanhou uma das etapas desse processo, Corina Moreira, num trabalho apresentado em um evento científico, referiu-se ao bem cultural em tela como "complexo religioso-cultural nominado como ‘Congadas”” (Moreira, 2015, p. 6). O outro documento é a dissertação de autoria de Rafael Barros Gomes sobre o referido processo e defendida no Programa de Mestrado Profissional em Preservação do Patrimônio Cultural do IPHAN, em 2015. O autor adota a expressão ב. "multiverso das 'Congadas”" (Gomes, 2015, p. Nิ 17), fazendo menção aos festejos. Decerto que

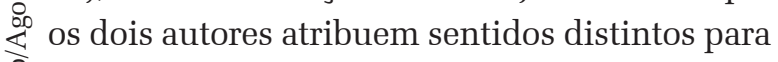
cada uma das expressões elencadas. No entanto, em ambos os casos, destacam não apenas as variações como também a complexidade do evento festivo posto em processo de registro.

${ }^{13}$ Não estive presente no encontro promovido pelo IPHAN em Uberlândia. No entanto, tive acesso aos slides produzidos pela equipe dessa instituição, que foram exibidos na ocasião e, posteriormente, disponibilizados por essa equipe aos interessados. negro ou catolicismo popular, embora existam estudos que as associam a religiões afro-brasileiras como a umbanda (Pereira; Gomes, 2000). Roger Bastide (1996), em suas "Américas Negras", as classificou como "folclore negro". Aliás, em estudos que tratam do folclore, essas festas são designadas folguedos (Martins, S., 1991), tendo sido até mesmo consideradas como uma das "danças dramáticas" descritas por Mário de Andrade (Andrade, 1982). ${ }^{14}$

Essa última categorização reverberou no livro $O$ Quilombismo, de Abdias do Nascimento (Nascimento, 1980). Nessa obra, Nascimento defende a ideia da constituição de um patrimônio negro comum entre os países da diáspora africana. O pan-africanismo foi, para Nascimento, uma inspiração para a criação de seu quilombismo: uma referência direta aos quilombos e que se definia como um projeto político global que propunha um Estado multicultural e igualitário. Para compor seu quilombismo, o autor menciona as "congadas ou congos", fazendo referência à forma como os africanos, no Brasil, forjaram suas próprias manifestações, reelaborando, à sua maneira, o catolicismo imposto pela Coroa portuguesa, ainda à época colonial.

A menção de Nascimento coaduna com os postulados de Roger Bastide (1995), quando esse último desenvolve seu entendimento sobre as sobrevivências africanas em terras brasileiras. Bastide considera as congadas, referindo-se a elas, ainda nos tempos coloniais, como nichos da África no Brasil, um exemplo de como os africanos conseguiram manter suas práticas religiosas apesar do catolicismo (Bastide, 1995). As formulações do autor referentes às sobrevivências africanas no Brasil, especificamente ao vasto universo religioso afro-brasileiro, foram e ainda são reinterpretadas por parte dos militantes do movimento negro - incluindo, no caso, Abdias do Nascimento -,

${ }^{14}$ Ressalto, aqui, o trabalho dos folcloristas no registro e na difusão das diferentes festas e práticas ao longo do século XX. Muitas delas foram classificadas como folclóricas e, atualmente, fazem parte das listas dos patrimônios culturais imateriais. Para uma análise sobre essa mudança, ver Mira (2014). 
ao defenderem a capacidade de resistência do negro frente à dominação do branco. E, na visão de parte desses militantes, as práticas que conseguiram "sobreviver" ao tempo devem ser preservadas. É esse um dos argumentos que justificam o apoio de parte do movimento negro à patrimonialização de práticas religiosas afro-brasileiras, como o candomblé, principalmente, no caso da Bahia, e as festas do Rosário, em Minas Gerais. ${ }^{15}$

\section{REGISTROS EM TENSÃO}

O processo de registro das festas do Rosário foi iniciado em um momento em que era crescente a incorporação aos patrimônios nacionais dos bens culturais relativos à cultura afro-brasileira (Capone; Morais, 2015). Tal fato também implica a composição dos patrimônios culturais estaduais e municipais. No caso das Festas do Rosário, em Minas Gerais, outros processos antecedem o do IPHAN. O governo do estado de Minas Gerais, por meio do Instituto Estadual do Patrimônio Histórico e Artístico (IEPHA), registrou duas festas como patrimônio cultural imaterial. A primeira foi a da Comunidade dos Arturos, em Contagem, na Região Metropolitana de Belo Horizonte, em 2014. Em 2015, foi registrada a festa realizada na cidade de Chapada do Norte, no Vale do Jequitinhonha, no norte do Estado.

Além dessas festas, já consideradas patrimônios mineiros, prefeituras várias têm buscado registrar os festejos que acontecem em seus municípios. ${ }^{16} \mathrm{Na}$ capital do Estado, Belo Horizonte, a Irmandade de Nossa Senhora do Rosário do Jatobá, localizada na região do Barreiro, foi tombada pela prefeitura, ou seja,

${ }^{15}$ A relação entre o movimento negro e o processo de patrimonialização de elementos da cultura afro-brasileira é abordada em Santos (2005) e Morais (2018).

${ }^{16}$ Em Minas Gerais, o governo estadual criou uma modalidade de incentivo fiscal, o ICMS Cultural, que tem contribuído para uma crescente implementação de ações patrimoniais por parte das prefeituras. As festas dedicadas ao Rosário de Maria têm sido alvo de muitas dessas ações.

Para uma reflexão sobre algumas dessas experiências, ver Martins, M. (2012). inscrita na lista dos bens culturais considerados patrimônios culturais materiais do município - fato ocorrido em 1995, antes mesmo da instituição do instrumento legal do registro do patrimônio imaterial no Brasil. Também na capital mineira, deu-se início, em 2012, ao processo de registro das festas do Rosário que ocorrem na cidade como patrimônio imaterial.

Busquei informar aqui algumas variações das - e sobre as - festas em louvor ao Rosário de Maria. Tais variações implicam, diretamente, o seu processo de registro como patrimônio cultural imaterial, impondo questões de cunho prático e (ou) de cunho conceitual aos diferentes grupos que dele participam. Conforme a norma que rege a constituição desses patrimônios (Brasil, 2000), eles devem ser inscritos em um - friso, apenas um - dos seguintes livros de registros: saberes; celebrações; formas de expressão; lugares. Uma primeira leitura poderia informar a inscrição das festas dedicadas ao Rosário de Maria no livro de registros das celebrações, já que se trata de uma festa que marca a vivência coletiva de um grupo, tal como é descrito pela norma.

No entanto, as festas são também uma forma singular de viver o fato coletivo, de perceber o mundo e com ele se relacionar (Perez, 2011). Assim, estão de acordo também com o exposto no livro dos saberes, onde constam os conhecimentos e os modos de fazer enraizados no cotidiano dos grupos, e mesmo no livro das formas de expressão, já que envolvem manifestações musicais, plásticas, cênicas e lúdicas. Uma vez que os patrimônios imateriais devem ser inscritos em um livro de registro, como categorizar uma festa que atende aos parâmetros estabelecidos em mais de um livro? Essa seria uma questão prática acerca do processo de patrimonialização das festas do Rosário, mas que tem implicações conceituais, pois está relacionada à própria construção da ideia de patrimônio imaterial.

Em um seminário ${ }^{17}$ ocorrido em 2015,

${ }^{17}$ Trata-se do "Seminário Saberes do Sagrado: Irmandades do Rosário e o Registro Patrimonial”, já mencionado na nota 8. 
em Belo Horizonte, em que se discutiu o processo de registro das Congadas de Minas, parte dos técnicos do IPHAN presentes na ocasião apontava as dificuldades que tinham em "enquadrar” as festas - não restringindo às festas do Rosário - nas categorias estabelecidas pelo próprio órgão gestor do chamado patrimônio nacional. Essa é uma das questões que surgem no atual contexto de ampliação de processos de "captura" das festas, dos rituais e das celebrações pelos dispositivos políticos postos em ação com as políticas públicas voltadas para o turismo e a patrimonialização (Perez, 2015).

Estudos no âmbito das ciências sociais, no Brasil (Abreu; Chagas, 2009) e no exterior (Bortolotto, 2011b; Jeudy, 2008), têm apontado, por exemplo, os limites conceituais do chamado patrimônio cultural imaterial. Apesar de ser ampla a definição de patrimônio cultural imaterial posta a partir da Convenção da UNESCO de $2003,{ }^{18}$ ela não comporta a complexidade das experiências humanas, pois, em muitas delas, não há como estabelecer uma dissociação entre o que é considerado material e o que é considerado imaterial, tal como classificam as normas que regem as ações patrimoniais. O Rosário de Maria é um exemplo disso: ele é a força que protege os devotos e também um objeto ritual. A própria festa dedicada ao Rosário de Maria, F entendida como um bem cultural imaterial pelo órgão gestor do patrimônio no Brasil, não acontece sem a manipulação dos bens materiais que a compõem, como, por exemplo, as roupas dos dançantes, os instrumentos musicais, a comida que é servida aos participantes, a igreja onde são realizados os ritos.

${ }^{18}$ A definição da Convenção da UNESCO é a adotada nos documentos brasileiros referentes ao patrimônio imate๗ื rial. Conforme tal convenção, "entende-se por "patrimônio

$>$ cultural imaterial' as práticas, representações, expressões,

ธิ conhecimentos e técnicas - junto com os instrumentos,

objetos, artefatos e lugares culturais que lhes são associa-

dos - que as comunidades, os grupos e, em alguns casos,

శ్ os indivíduos reconhecem como parte integrante de seu

patrimônio cultural. Este patrimônio cultural imaterial,

Tue se transmite de geração em geração, é constantemente

Ð recriado pelas comunidades e grupos em função de seu

- ambiente, de sua interação com a natureza e de sua histó-

ria, gerando um sentimento de identidade e continuidade

e contribuindo assim para promover o respeito à diversi-

dade cultural e à criatividade humana" (UNESCO, 2003). do, a constituição dos patrimônios culturais imateriais está relacionada ao discurso que confere à globalização a capacidade de homogeneizar as culturas, ameaçando a diversidade cultural no planeta. ${ }^{19}$ Com o estabelecimento desses patrimônios, buscava-se a preservação das "culturas tradicionais", evitando seu desaparecimento e garantindo a dita diversidade. O argumento que permeia a constituição dos patrimônios imateriais está fundado, assim, na alegoria da perda.

Porém, no caso do registro das Congadas de Minas como patrimônio cultural do Brasil, trata-se de festas religiosas, quando é produzido o fato coletivo (Amaral, 1998; Da Matta, 1978; Durkheim, 1996; Perez, 2011, 2015). Como foi mencionado anteriormente, as festas são capazes de recriar a si próprias - vide as variações das festas dedicadas ao Rosário de Maria - e, consequentemente, a vida social. Conforme Jean Duvignaud (1983, p. 222), as festas permitem "às pessoas e coletividades sobrepujarem a 'normalidade' e chegarem ao estado onde tudo se torna possível porque o indivíduo, então, não se inscreve apenas em sua essência humana, porém, em uma natureza que ele completa pela sua experiência”.

As festas religiosas já até tiveram o seu fim decretado no passado, mas, em função de seu caráter subversivo, como afirma Léa Perez (2011), teimam em se manter vivas. Como é o caso das festas dedicadas ao Rosário de Maria, que, mesmo após serem proibidas e perseguidas pela Igreja Católica, ainda no século $\mathrm{XX}$, em especial na sua primeira metade, se multiplicam e se pluralizam nos rincões mineiros e também nas periferias dos grandes centros urbanos de Minas Gerais. ${ }^{20}$ São festas que guardam suas complexidades, evidenciando que um único evento festivo pode reunir características específicas relacionadas a dis-

${ }^{19}$ Apesar de uma dada permanência desse discurso, principalmente no que tange às políticas patrimoniais, a literatura das ciências sociais tem apontado a capacidade criativa das culturas, mesmo diante da globalização (Sahlins, 1997).

${ }^{20}$ A literatura também registra restrições à realização dessas festas em outros períodos da história brasileira (Cf. Kiddy, 2005; Mello; Souza, 2006). 
tintas formas de categorização, sem se deixar definir, necessariamente, por nenhuma delas (Perez, 2015).

Dessa forma, o argumento que justifica as ações patrimoniais que têm como objeto os bens culturais ditos imateriais está em tensão com a própria dinâmica das festas, em especial as dedicadas ao Rosário de Maria, foco do processo de patrimonialização em curso no âmbito do IPHAN. Ou, em outras palavras, trata-se de uma tensão entre o vivido e a prática estatal. Uma tensão que não se impõe como uma força contrária ao processo de patrimonialização, tendo em vista o fato de grupos de outros estados brasileiros (São Paulo, Espírito Santo e Goiás) terem recorrido ao IPHAN, após a solicitação mineira, para que os festejos que eles organizam para louvar o Rosário de Maria também pudessem ser reconhecidos como patrimônio.

Aliás, a patrimonialização tem sido acionada por diferentes comunidades afro-religiosas afim de assegurarem seus direitos. Há casos, por exemplo, que a patrimonialização impede que o grupo perca o território onde realiza suas práticas religiosas devido à processos urbanos decorrentes da especulação imobiliária. A patrimonialização também é um recurso mobilizado por essas comunidades na luta contra os crescentes casos de intolerância religiosa dos quais são vítimas. Dessa maneira, a patrimonialização torna-se, assim, um instrumento para garantir a manutenção de suas práticas.

Talvez essa tensão entre o vivido e a prática estatal seja inerente à própria patrimonialização, como pode ser observado em uma experiência local descrita no último tópico deste artigo. ${ }^{21}$ Apresento, assim, algumas considerações sobre a patrimonialização da Irmandade de Nossa Senhora do Rosário do Jatobá, cujo processo, acredito, lança luz àquele corrente no plano nacional.

${ }^{21}$ De fato, essa tensão não se observa apenas no caso do registro das festas dedicadas ao Rosário de Maria. Ela pode ser pensada como constitutiva das próprias políticas patrimoniais. Em outras arenas da política pública também se observa uma tensão entre os argumentos que constituem base para uma determinada ação e a realidade vivenciada pelos grupos que são foco dela (Jayme; Trevisan, 2012). Ou mesmo entre o que está posto pela teoria social e o vivido em situações específicas (Andrade; Jayme; Almeida, 2009).

\section{RESSONÂNCIA JUNTO AO PÚBLICO?}

A Irmandade de Nossa Senhora do Rosário do Jatobá foi tombada em 1995, na mesma ocasião em que se deu o tombamento de um terreiro de candomblé, também em Belo Horizonte, o Ilê Wopo Olojukan. Os dois tombamentos ocorreram como parte das celebrações do tricentenário de Zumbi dos Palmares e tiveram a participação direta do movimento negro que, à época, contava com a presença de parte de sua militância nos quadros da administração municipal, em especial, nos órgãos de gestão da política cultural. O terreiro e a irmandade foram considerados, nos processos de tombamento, como locus de resistência dos negros frente à dominação branca. Ao elegerem uma Irmandade de Nossa Senhora do Rosário para ser tombada como patrimônio cultural de Belo Horizonte, defendendo a ideia de que ali se constituía um "marco da resistência negra", os integrantes do movimento negro - que se articulavam em torno da política cultural, buscando integrar ações que valorizassem a população negra - reinterpretavam os apontamentos teóricos de Roger Bastide incorporados no discurso político de Abdias do Nascimento. Eles faziam uso da mesma argumentação de Bastide e de Nascimento, uma vez que mantinham a ideia de resistência negra frente aos brancos, adotada pelos dois autores ao tratarem do candomblé. E, no caso da irmandade, essa ideia era reforçada pelo fato de se ter comprovado a existência dos festejos a Nossa Senhora do Rosário antes da fundação da cidade.

Em textos assinados por militantes negros e publicados após o tombamento da irmandade, sempre há menção ao tombamento como parte das celebrações do tricentenário de Zumbi dos Palmares. No entanto, no dossiê da Irmandade do Jatobá, não há qualquer referência a tal celebração. Acredito que a ausência da menção da celebração no dossiê da Irmandade do Jatobá está relacionada com a própria forma como parte de seus integrantes lidaram, e ain- 
da lidam, com a patrimonialização. O processo foi iniciado a pedido do então capitão-mor João Lopes, como está documentado no dossiê e ainda hoje é comentado no grupo desses integrantes. É corrente ouvir, entre eles, que a irmandade tinha uma alta dívida de um imposto municipal, um montante que não conseguiria pagar com os parcos recursos que recolhe mensalmente por meio de doações. O tombamento foi uma saída encontrada por João Lopes para não perder o terreno onde está a Irmandade do Jatobá, uma explicação que me foi relatada repetidas vezes por seus integrantes.

Chamo a atenção para o fato de que, até hoje, não há marco físico algum que sinalize ao visitante que a Irmandade do Jatobá é um patrimônio cultural de Belo Horizonte, diferentemente do terreiro de candomblé, onde foi instalada, com destaque, uma placa informando o tombamento. À época, a matriarca da irmandade, Dona Maria Ferreira, não permitiu a instalação de uma placa com tal informação, temendo intervenções da Prefeitura e que o patrimônio da irmandade se tornasse público - usando aqui o termo em seu sentido primeiro, o de propriedade. Dona Maria faleceu em 2005 e, na Irmandade do Jatobá, ainda não foi instalado qualquer marco físico indicando ser ela um patrimônio cultural belo-horizontino.

Nem o documento entregue à Irmandade do Jatobá pela Prefeitura de Belo Horizonte, quando de seu tombamento, declarando-a um patrimônio cultural da cidade foi conservado. Não se sabe quando, mas entre uma e outra gestão da diretoria da irmandade, o documento desapareceu. É claro que a perda de um documento, por si só, não indica uma rejeição do tombamento, nem é essa a interpretação que tenho para o fato. A perda do documento remete também a questões internas da irmandade, à própria forma como ela se organiza administrativamente e à dificuldade que seus integrantes têm para tratar dos assuntos que envolvem a burocracia estatal. Mas esse fato - somado à ausência ainda hoje da placa e, principalmente, ao motivo primeiro que levou o então capitão-mor do Jatobá, João Lopes, a solicitar o tombamento - aponta que os argumentos enunciados pelo movimento negro destoavam da experiência daqueles que se congregam em irmandade no Reinado do Jatobá.

Em sua análise sobre a relação dos praticantes do candomblé baiano com o movimento negro, Jocélio Teles dos Santos afirma que, por parte dos candomblecistas, não havia uma "racialização à la movimentos negros", mas eles buscavam legitimar e reforçar "simbolicamente a sua religião através de novos conteúdos políticos” (Santos, 2005, p. 169). Transpondo para o caso da Irmandade do Jatobá, não haveria por parte do grupo o intento de "racializar" sua prática religiosa. A memória da escravidão, a África mítica, a ancestralidade negra, exaltadas no discurso do movimento negro - o que lhes confere status de resistência -, são parte do cotidiano religioso daquela irmandade.

Penso que a postura da Irmandade do Jatobá perante a patrimonialização condiz com os apontamentos de José Reginaldo Santos Gonçalves (2005), ao abordar os desafios impostos às agências estatais a partir da criação de mecanismos legais que contemplam patrimônios fortemente relacionados com a experiência, como as festas religiosas. Segundo o autor, nesses casos, há uma permanente tensão entre o cotidiano vivido pelos devotos e a classificação do patrimônio cultural desenvolvida pelas agências estatais. Tal classificação é parcialmente assumida pelos devotos, ou mesmo rejeitada por eles, uma vez que nem sempre os bens culturais classificados como patrimônio encontram respaldo ou reconhecimento dos grupos. O autor enfatiza que a constituição de um patrimônio cultural não depende apenas da vontade e da decisão políticas, tampouco de uma atividade consciente e deliberada de indivíduos ou grupos. Faz-se necessário que ela encontre "ressonância" em seu público.

Desde que passei a acompanhar os festejos do Rosário na Irmandade do Jatobá, em 2012, várias foram as reações de surpresa por parte dos meus interlocutores quando lhes ex- 
plicava o tema da minha pesquisa: "Ih... patrimônio? Não vai encontrar nada aqui não... A prefeitura nem vem aqui..." - me contou uma congadeira logo no início do trabalho de campo. "Achava que patrimônio eram os Arturos!" - disse-me uma devota fazendo referência ao grupo localizado em Contagem. "O que é patrimônio?" - me perguntou um integrante do Reino que participa dos festejos desde pequeno. "Patrimônio pra mim é tudo que pertence à irmandade" - afirmou um congadeiro, referindo-se ao imóvel registrado em nome da irmandade, usando o termo "patrimônio" no sentido de propriedade.

Esses breves relatos reforçam a tensão entre o cotidiano dos devotos e as classificações adotadas pelas agências estatais nos processos de patrimonialização. Mas eles também indicam uma ausência de acompanhamento do próprio poder público, no caso a administração municipal, de um bem cultural eleito patrimônio do município. O processo de patrimonialização da Irmandade do Jatobá ocorreu em um momento em que havia uma junção de interesses: a administração municipal, que reestruturava sua política patrimonial; o movimento negro, que iniciava a construção de ações voltadas para a população negra no âmbito da administração municipal; e a irmandade, que necessitava solucionar um problema burocrático e financeiro. Nos mais de vinte anos decorridos do tombamento, não houve, até 2018, ação específica alguma da administração municipal que envolvesse a irmandade. É como se o bem patrimonializado estivesse encerrado nos livros de tombo, uma vez que não é partícipe do cotidiano da política pública.

Os relatos mencionados são ilustrativos do descompasso entre uma decisão política e a vivência de parte dos devotos, uma vez que há também, entre os integrantes da irmandade, aqueles que atentam para questões relativas ao patrimônio, principalmente os que lidam com a estrutura administrativa. O próprio João Lopes, ao recorrer à patrimonialização, estava buscando meios não somente de manter o imóvel do grupo como também de cuidar para que seu passado não se esvaísse. Essa era uma preocupação por ele externada, motivando, em 1993, a produção de um livro sobre a Irmandade do Jatobá, o Afrografias da memória, de Leda Maria Martins, atual rainha de Nossa Senhora das Mercês da Irmandade (Martins, L., 1997). João Lopes faleceu em 2004. Na Irmandade do Jatobá, os festejos continuam anualmente. O reinado é aberto no sábado de aleluia, os festejos ocorrem na segunda quinzena de agosto, e, no último sábado de outubro, encerra-se o ciclo festivo. Mas, desde a morte desse grande anganga muquiche, a capitania-mor teve momentos de intermitência, fazendo o cântico entoado pela Guarda de Congo de São Benedito da Irmandade do Jatobá se perpetuar:

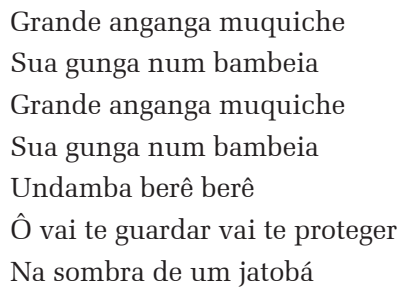

Anganga muquiche é o sacerdote do Rosário, que, no Jatobá, tem João Lopes como o mais celebrado hoje. Gunga é uma espécie de chocalho que os moçambiqueiros atam quase junto aos pés. Gunga também é a magia que investe os congadeiros, dando-lhes força para louvar o Rosário de Maria. Quando eles dançam louvando a Virgem, a evocam nas forças ancestrais de Undamba berê berê, que guarda e protege aqueles que fazem o Reinado do Jatobá, onde a gunga de seu grande anganga muquiche segue em riste, ou teima em manter-se viva, nos mostrando uma forma singular de viver uns com os outros, festejando o Rosário de Maria.

Recebido para publicação em 06 de agosto 2018 Aceito em 06 de agosto de 2019 


\section{REFERÊNCIAS}

ABREU, R.; CHAGAS, M. (Org.). Memória e patrimônio: ensaios contemporâneos. Rio de Janeiro: Lamparina, 2009.

AMARAL, R. Festa à brasileira - sentidos do festejar no país que "não é sério”. 1998. Tese (Doutorado em Antropologia Social) - Faculdade de Filosofia, Letras e Ciências Humanas, Universidade de São Paulo, São Paulo, 1998.

ANDRADE, L. T. de; JAYME, J. G.; ALMEIDA, R. de C. Espaços públicos: novas sociabilidades, novos controles. Cadernos metrópole (PUC-SP), São Paulo, v. 21, p. 131153, 2009

ANDRADE, M. de. Danças dramáticas do Brasil. Belo Horizonte: Editora Itatiaia, 1982.

ARANTES, A. A. Produzindo o passado: estratégias de construção do patrimônio cultural. São Paulo: Brasiliense, 1984.

BASTIDE, R. Les religions africaines au Brésil. Paris: PUF, 1995.

BASTIDE, R. Les Amériques noires. Prefácio de J. Benoist. Lille: Ed. L'Harmattan, 1996.

BORTOLOTTO, C. Le trouble du patrimoine culturel immatériel. In: BORTOLOTTO, C. (Org.). Le patrimoine culturel immatériel: enjeux d'une nouvelle catégorie. Paris: Éditions de la Maison des Sciences de l’Homme, 2011a.

BORTOLOTTO, C. (Org.). Le patrimoine culturel immatériel: enjeux d'une nouvelle catégorie. Paris: Éditions de la Maison des Sciences de l'Homme, 2011b.

BRASIL. Constituição (1988). Constituição da República Federativa do Brasil. Brasília: Senado, 1988. Disponível em: https://www.planalto.gov.br/ccivil_03/constituicao/ constituicao.htm. Acesso em: 3 ago. 2018.

BRASIL. Decreto-lei $n^{o} 25$, de 30 de novembro de 1937. Organiza a proteção do patrimônio histórico e artístico nacional. Brasília: Palácio do Planalto, 1937. Disponível em: https://www.planalto.gov.br/ccivil_03/decreto-lei/ Del0025.htm. Acesso em: 3 ago. 2018.

BRASIL. Decreto $n^{o}$ 3.551, de 4 de agosto de 2000. Institui o Registro de Bens Culturais de Natureza Imaterial que constituem patrimônio cultural brasileiro, cria o Programa

Nacional do Patrimônio Imaterial e dá outras providências.

๑ Brasília: Palácio do Planalto, 2000. Disponível em: https://

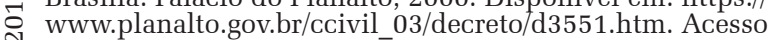
. em: 3 ago. 2018.

¿ CAPONE, S.; MORAIS, M. R. de (Org.). Afro-patrimoines: culture afro-brésilienne et dynamiques patrimoniales. Les สarnets du lahic, Paris, n. 11, 2015. Disponível em: http:// www.iiac.cnrs.fr/article2813.html. Acesso em: 3 ago. 2018.

+ CHUVA, M. R. R. Os arquitetos da memória: sociogênese เo das práticas de preservação do patrimônio cultural no ₹ Brasil (1930-1940). Rio de Janeiro: Editora UFRJ, 2009.

2 DA MATTA, R. Carnavais, malandros e heróis: para uma $\stackrel{0}{\infty}$ sociologia do dilema brasileiro. Rio de Janeiro: Zahar, ¿. 1978 .

๗ิ DURKHEIM, É. As formas elementares da vida religiosa. $>$ São Paulo: Martins Fontes, 1996.

oิ DUVIGNAUD, J. Festas e civilizações. Fortaleza: U. Universidade Federal do Ceará, 1983.

స్ FABRE, D. Le Patrimoine, l'ethnologie. In: NORA, P. (Org.). T. Science et conscience du patrimoine. Paris: Fayard, 1997.

FONSECA, M. C. L. O patrimônio em processo: trajetória da política federal de preservação no Brasil. Rio de Janeiro: Editora UFRJ: IPHAN, 1997.

GOMES, R. B. Minha fé não é cultura: a eficácia da magia e as amarras do estado. 2015. Dissertação (Mestrado Profissional em Preservação do Patrimônio) - Instituto do Patrimônio Histórico e Artístico Nacional, Rio de Janeiro, 2015.

GONCALVES, J. R. S. A retórica da perda: os discursos do patrimônio cultural no Brasil. Rio de Janeiro: Editora UFRJ: IPHAN, 1996.

GONÇALVES, J. R. S. Ressonância, materialidade e subjetividade: as culturas como patrimônios. Horizontes antropológicos, Porto Alegre, v. 11, n. 23, p. 15-36, jan./ jun. 2005.

JAYME, J. G.; TREVISAN, E. Intervenções urbanas, usos e ocupações de espaços na região central de Belo Horizonte. Civitas: revista de Ciências Sociais, Porto Alegre, v. 12, p. 359-377, 2012.

JEUDY, H.-P. La machinerie patrimoniale. Belval: Circé, 2008 .

KIDDY, E. W. Blacks of the Rosary: memory and history in Minas Gerais, Brazil. Pennsylvania: Penn State University Press, 2005.

LUCAS, G. Os sons do Rosário: o congado mineiro dos Arturos e do Jatobá. Belo Horizonte: Editora UFMG, 2014.

MARTINS, L. M. Afrografias da memória: o reinado do Rosário no Jatobá. São Paulo: Perspectiva; Belo Horizonte: Mazza, 1997.

MARTINS, M. da C. O registro do patrimônio cultural imaterial: considerações sobre o processo de materialização do intangível nas festas religiosas. 2012. Dissertação (Mestrado em Sociologia) - Faculdade de Filosofia e Ciências Humanas, Universidade Federal de Minas Gerais, Belo Horizonte, 2012.

MARTINS, S. Folclore em Minas Gerais. Belo Horizonte: Editora UFMG, 1991.

MELLO E SOUZA, M. Reis negros no Brasil escravista: história da festa de coroação de Rei Congo. Belo Horizonte: Editora UFMG, 2006.

MIRA, M. C. Entre a beleza do morto e a cultura viva: mediadores da cultura popular na São Paulo da virada do milênio. 2014. Tese (Livre-docência em Antropologia e Sociologia da Cultura) - Pontifícia Universidade Católica de São Paulo, São Paulo, 2014.

MORAIS, M. R. de. De religião a cultura, de cultura a religião: travessias afro-religiosas no espaço público. Belo Horizonte: Editora PUC Minas, 2018.

MOREIRA, C. M. R. Construindo uma narrativa patrimonial: as congadas de Minas. In: ENCONTRO TRICORDIANO DE LINGUÍSTICA E LITERATURA, 5., 2015, Três Corações. Anais [...] Três Corações: Unincor, 2015.

NASCIMENTO, A. do. O quilombismo: documentos de uma militância pan-africanista. Petrópolis: Vozes, 1980.

ORGANIZAÇÃO DAS NAÇÕES UNIDAS PARA A EDUCAÇÃO, A CIÊNCIA E A CULTURA (UNESCO). Convenção para a salvaguarda do patrimônio cultural imaterial. 2003. Disponível em: http://www.unesco.org/ culture/ich/doc/src/00009-PT-Portugal-PDF.pdf. Acesso em: 3 ago. 2018.

PEREIRA, E. de A.; GOMES, N. P. de M. Negras raízes mineiras: os Arturos. Belo Horizonte: Mazza Edições, 2000.

PEREZ, L. F. Festa, religião e cidade: corpo e alma do Brasil. Porto Alegre: Medianiz, 2011.

PEREZ, L. F. Sagrado, festa e patrimônio: questões e dúvidas quanto ao seu processo de patrimonialização. In: SEMINÁRIO SABERES DO SAGRADO: IRMANDADES DO ROSÁRIO E O REGISTRO PATRIMONIAL, 1., 2015, Belo Horizonte. Anais [...] Belo Horizonte: Crespial, 2015. 
PEREZ, L. F.; MARTINS, M. da C.; GOMES, R. B. Variações sobre o reinado: um rosário de experiências em louvor a Maria. Porto Alegre: Medianiz, 2014.

RUBINO, S. As fachadas da história: os antecedentes, a criação e os trabalhos do Serviço do Patrimônio Histórico e Ártístico Nacional, 1937-1968. 1992. Dissertação (Mestrado em Antropologia Social) - Universidade Estadual de Campinas, Campinas, 1992.

SAHLINS, M. O "pessimismo sentimental” e a experiência etnográfica: por que a cultura não é um "objeto" em via de extinção (parte 1). Mana, Rio de Janeiro, v. 3, n. 1, p. 41-73, abr. 1997.

SALVAGUARDA. In: DICIONÁRIO Houaiss, 2019 Disponível em: https://houaiss.uol.com.br/pub/apps/ www/v3-3/html/index.php\#1. Acesso em: 23 ago. 2019.
SANT'ANNA, M. (Org.). O registro do patrimônio imaterial: dossiê final das atividades da Comissão e do Grupo de Trabalho Patrimônio Imaterial. Brasília: Edições do Patrimônio: IPHAN, 2012

SANTOS, J. T. dos. O poder da cultura e a cultura no poder: a disputa simbólica da herança cultural negra no Brasil. Salvador: Edufba, 2005.

SILVA, R. A. da. A atualização de tradições: performances e narrativas afro-brasileiras. São Paulo: LCTE, 2012.

TORNATORE, J.-L. L'esprit du patrimoine. Terrain, Paris, n. 55 , p. 106-127, set. 2010. 


\section{THE HERITAGIZATION OF THE OUR LADY OF THE ROSARY'S FESTIVALS: between social life and state's practices}

\section{Mariana Ramos de Morais}

This paper is about the heritagization of the Our Lady of the Rosary's festivals, also named "Congadas de Minas", in Brazil. This process started in 2008 by the Brazilian federal agency for cultural heritage, Instituto do Patrimônio Histórico e Artístico Nacional (IPHAN). The immaterial cultural heritage policy is based on the statement that the globalization threatens the cultural diversity in the planet. For that reason, some cultural practices, such as the Our Lady of the Rosary's festivals, should be preserved. Nevertheless, in this specific case, the cultural practice is a festival. The festivals, especially the religious ones, are the moment when the collective phenomenon that animates social life is produced. Because of their own dynamic, the festivals do not have a risk to disappear. Therefore, the argument that bases the heritagization policies is in conflict with the dynamic of the Our Lady of the Rosary's festivals.

KeYwORDs: Festival. Our Lady of the Rosary. Immaterial cultural heritage. Safeguarding. Globalization.

\section{LES FETES DU ROSAIRE EN TANT QUE PATRIMOINE: entre le vecu et la pratique de l'état}

\section{Mariana Ramos de Morais}

Cet article porte sur la patrimonialisation de fêtes en hommage à Notre-Dame du Rosaire, appelée aussi "Congadas de Minas", au Brésil. Depuis 2008, ce processus est en cours parl'organismegouvernemental en charge de la politique du patrimoine, l'Instituto do Patrimônio Histórico e Artístico Nacional (IPHAN). Cette action patrimoniale est inscrite dans le controversé domaine du patrimoine culturel immatériel, diffusé globalement par l'Unesco et basé sur le discours selon lequel la mondialisation a la capacité d'homogénéiser les cultures. La diversité culturelle de la planète serait, ainsi, menacée. À cause de cela, les États devraient préserver quelques pratiques culturelles. Cependant, le cas mentionné faire référence aux fêtes, notamment aux fêtes religieuses, qui sont le moment de la production du fait collectif, de la vie sociale. De cette façon, grâce à sa propre dynamique, ces fêtes ne sont pas menacées de disparition. Par conséquent, l'argumentation de l'État pour mise en patrimoine les fêtes de NotreDame du Rosaire est en conflit avec la dynamique de ces fêtes.

Mots-CLÉs: Fête. Notre-Dame du Rosaire. Patrimoine culturel immatériel. Sauvegarde. Mondialisation. en Sciences Sociales (EHESS), França. Pesquisadora associada do Centre d'Études en Sciences Sociales du Religieux (CéSor), da EHESS. Autora dos livros Nas teias do sagrado: registros da religiosidade afrobrasileira em Belo Horizonte, de 2010; Banda de cá, banda de lá: Umbanda para crianças, de 2012; De religião a cultura, de cultura a religião: travessias afro-religiosas no espaço público (sua principal publicação), de 2018; Co-organizadora, com Stefania Capone, da publicação Afro-Patrimoines: culture afro-brésilienne et dynamiques patrimoniales, de 2015. 